\title{
Self-Supported Copper Oxide Electrocatalyst for Water Oxidation at Low Overpotential and Confirmation of Its Robustness by $\mathrm{Cu}$ K-edge X-ray Absorption Spectroscopy
}

Xiang Liu, ${ }^{a}$ Shengsheng Cui, ${ }^{a}$ Zijun Sun, ${ }^{a}$ Yang Ren,,${ }^{\mathrm{b}}$ Xiaoyi Zhang, ${ }^{\mathrm{b}}{ }^{\text {Pingwu Du}}{ }^{* \mathrm{a}}$

${ }^{a}$ CAS Key Laboratory of Materials for Energy Conversion, Department of Materials Science and Engineering, $i$ ChEM (Collaborative Innovation Center of Chemistry for Energy Materials), University of Science and Technology of China (USTC), Hefei, 230026, China

${ }^{\mathrm{b}}$ X-ray Sciences Division, Argonne, National Laboratory, 9700 South Cass Avenue, Argonne, Illinois 60439, United States

*Corresponding author: dupingwu@ustc.edu.cn, xyzhang@aps.anl.gov

Tel/Fax: 86-551-63606207 


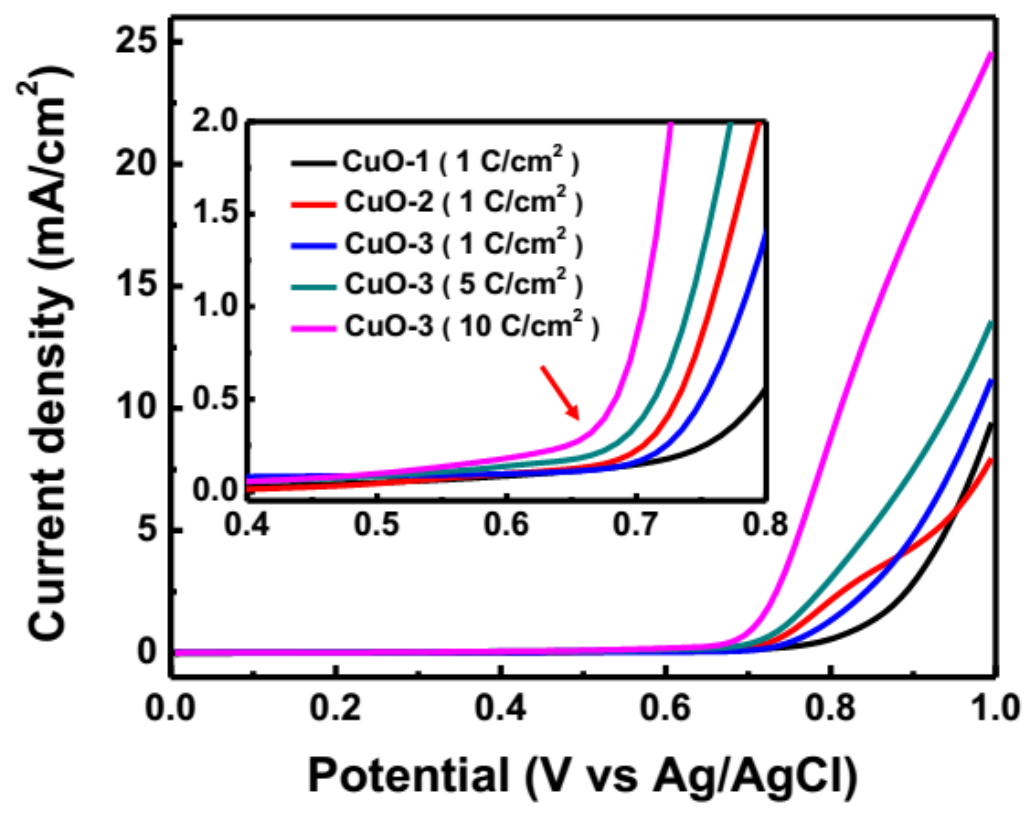

Figure S1. LSVs for CuO-1 (black), CuO-2 (red) and CuO-3 (blue) at the same charge quantity of $1 \mathrm{C} / \mathrm{cm}^{2}$ in $0.1 \mathrm{M} \mathrm{KOH}$. The dark cyan and the pink lines are represented for the $\mathrm{CuO}-3$ samples at 5 and $10 \mathrm{C} / \mathrm{cm}^{2}$. 

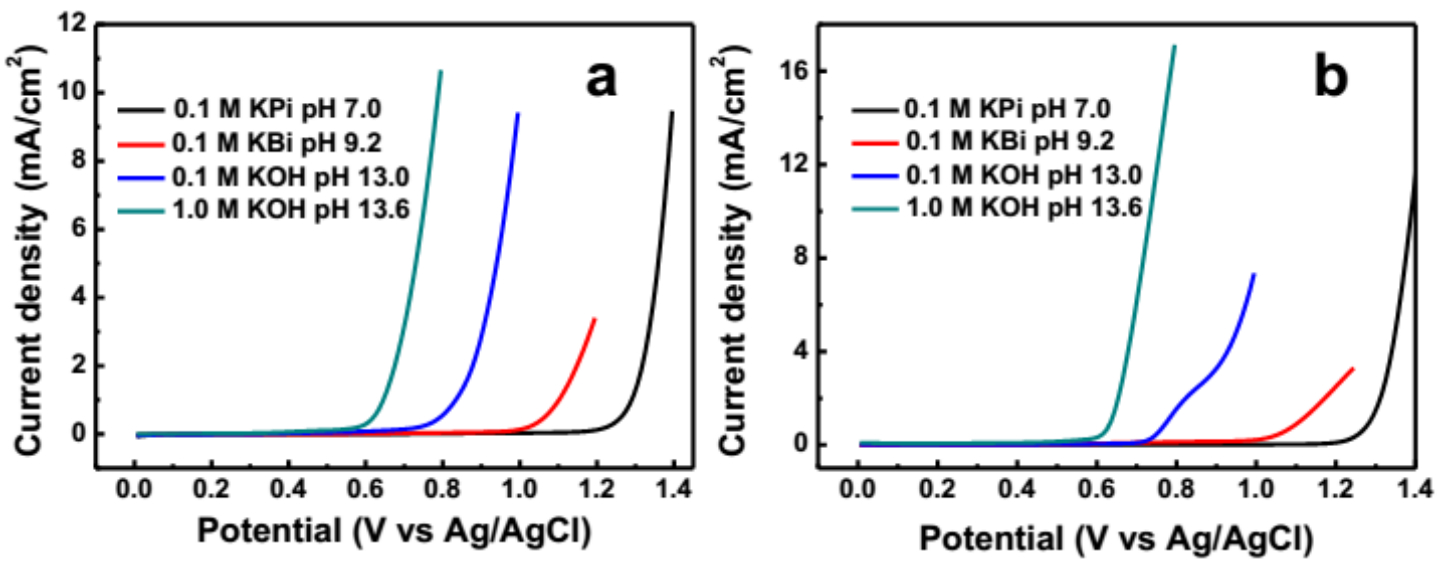

Figure S2. LSVs obtained by using CuO-1 (a) and $\mathrm{CuO}-2$ (b) as the catalysts for water oxidation in different electrolytes. 

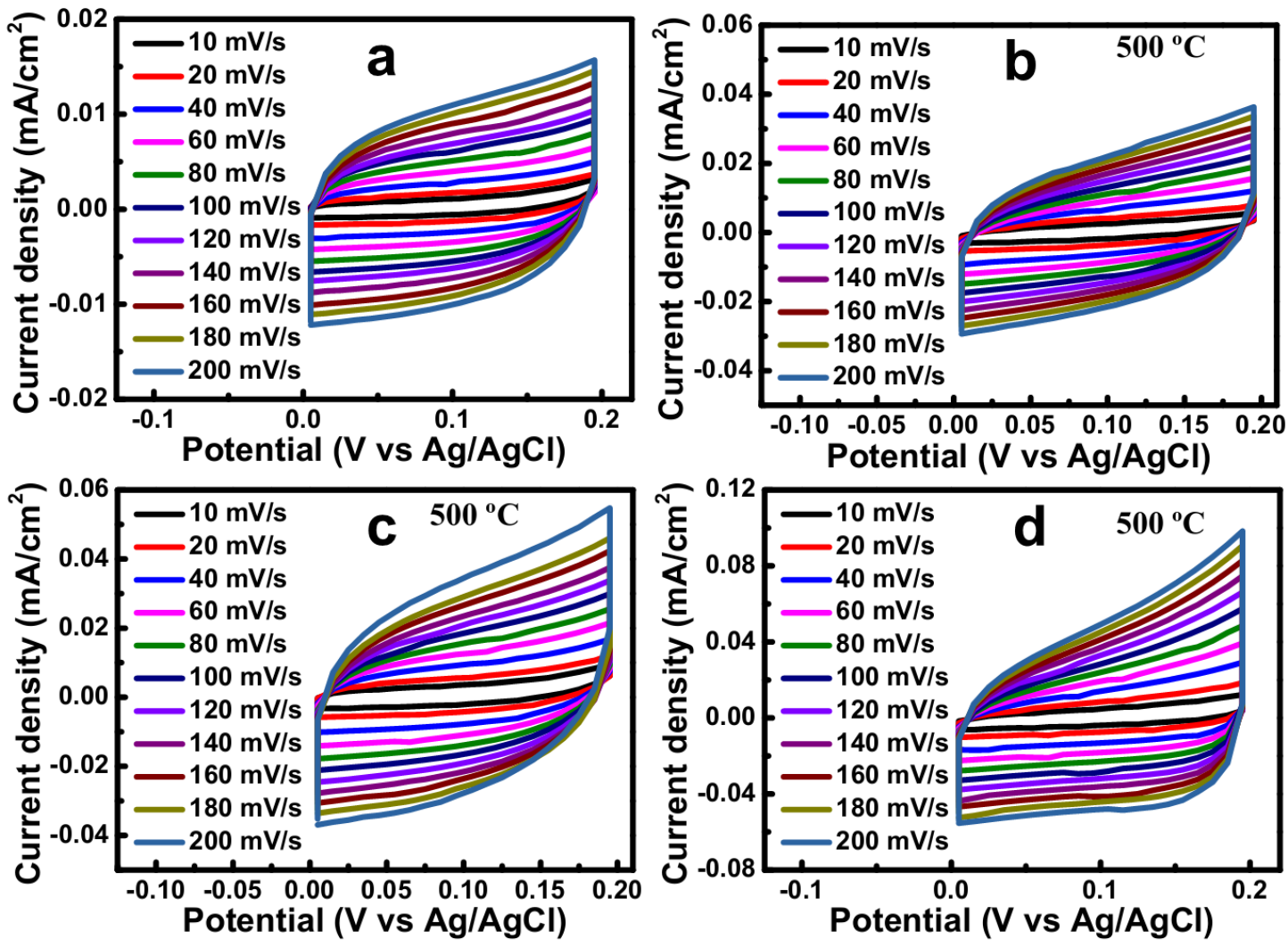

Figure S3. CVs of (a) bare glassy carbon electrode, (b) $\mathrm{CuO}-1$, (c) $\mathrm{CuO}-2$, and (d)

CuO-3 from 0 to $+0.2 \mathrm{~V}$ vs. $\mathrm{Ag} / \mathrm{AgCl}$ at various scan rate in $1.0 \mathrm{M} \mathrm{KOH}$ solution. All three $\mathrm{CuO}$ samples are annealed at $500{ }^{\circ} \mathrm{C}$. 


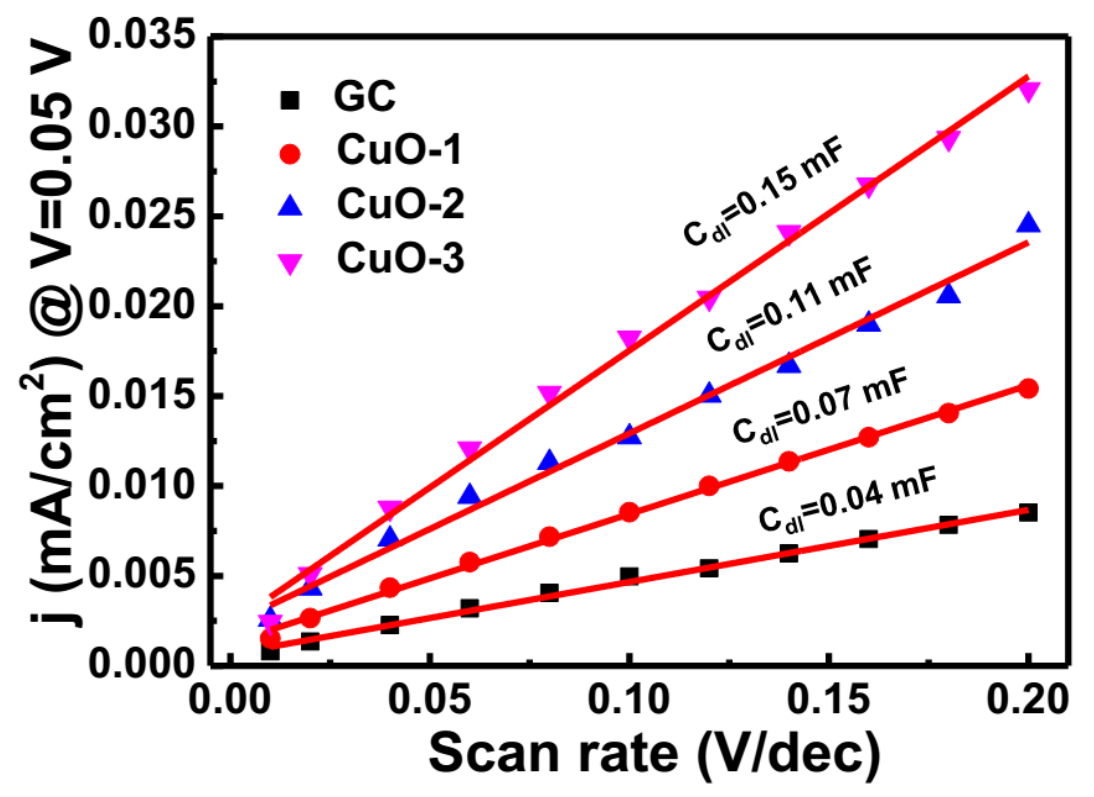

Figure S4. The anodic current density measured at $0.05 \mathrm{~V}$ vs. $\mathrm{Ag} / \mathrm{AgCl}$ as a function of scan rate for clear $\mathrm{GC}$ electrode, $\mathrm{CuO}-1, \mathrm{CuO}-2$ and $\mathrm{CuO}-3$ obtained from Figure S3. 

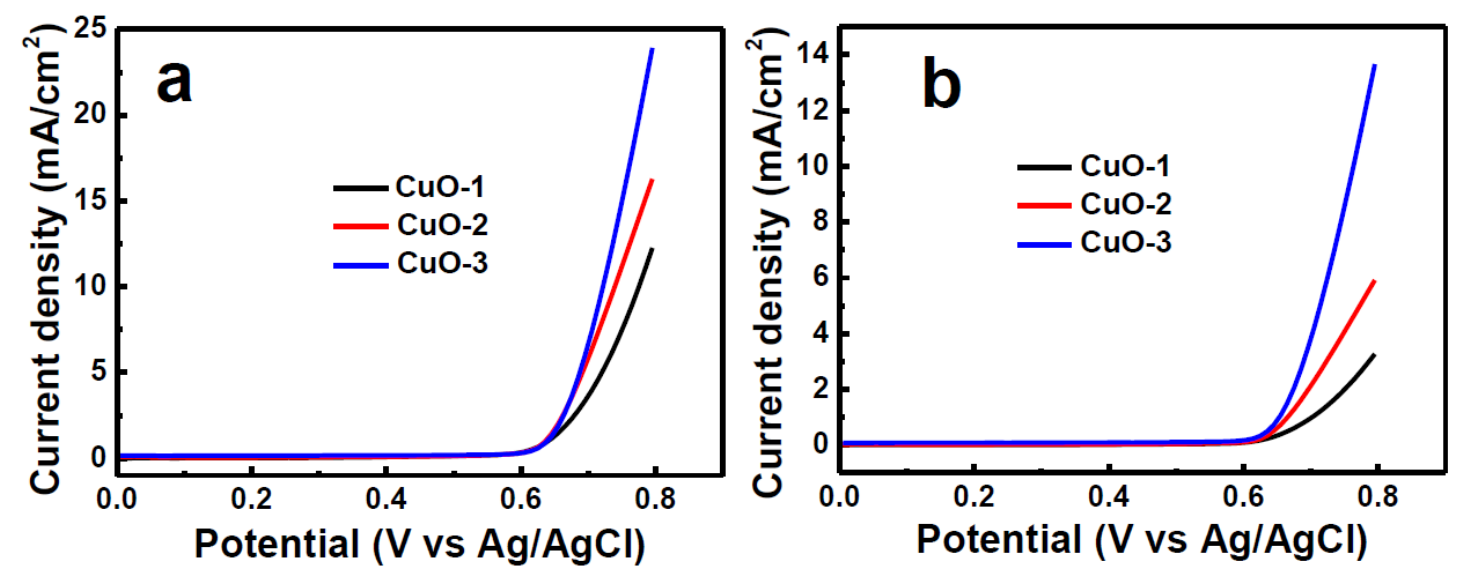

Figure S5. (a) LSVs of CuO-1, CuO-2, and $\mathbf{C u O - 3}$ on glassy carbon electrode in 1.0 M KOH based on the geometric area $\left(0.071 \mathrm{~cm}^{2}\right)$. (b) LSVs of CuO-1, CuO-2 and CuO-3 in $1 \mathrm{M} \mathrm{KOH}$ based on their ECSA $\left(3.75 \mathrm{~cm}^{2}\right.$ for $\mathbf{C u O - 3 ,} 2.75 \mathrm{~cm}^{2}$ for $\mathbf{C u O - 2}$, $1.75 \mathrm{~cm}^{2}$ for $\mathbf{C u O - 1}$ ) under the same conditions with (a). 


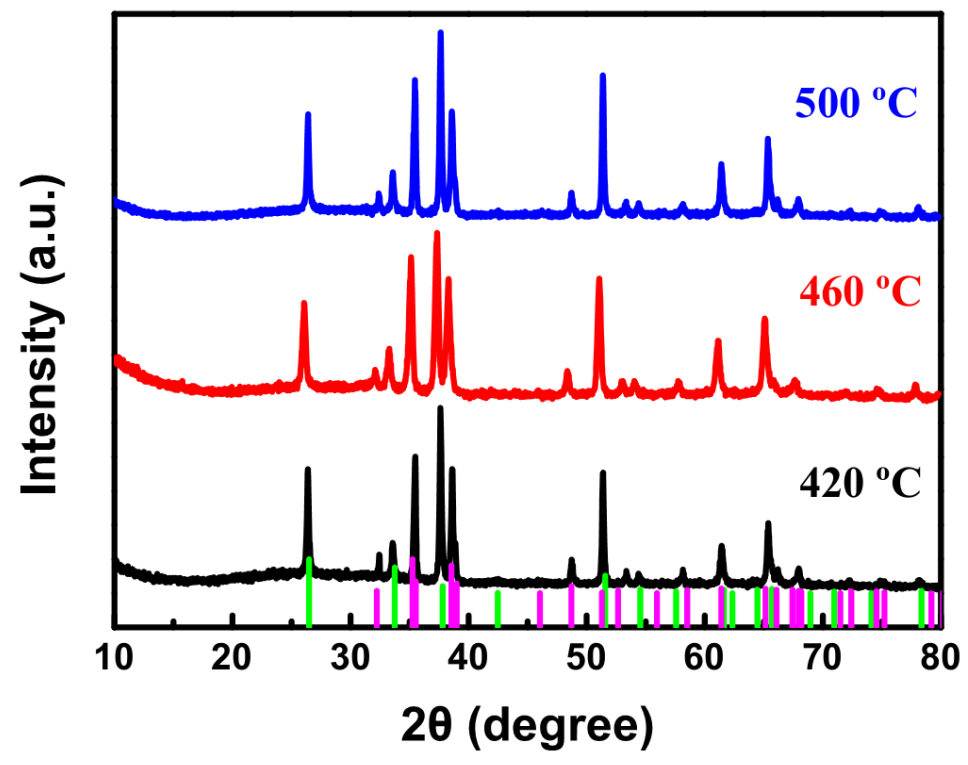

Figure S6. XRD patterns of CuO-3 sample on FTO annealed at different temperatures. The green and the pink lines at the bottom represent $\mathrm{CuO}$ PDF \#58-8595 and $\mathrm{SnO}_{2}$ PDF \#77-0452, respectively. 

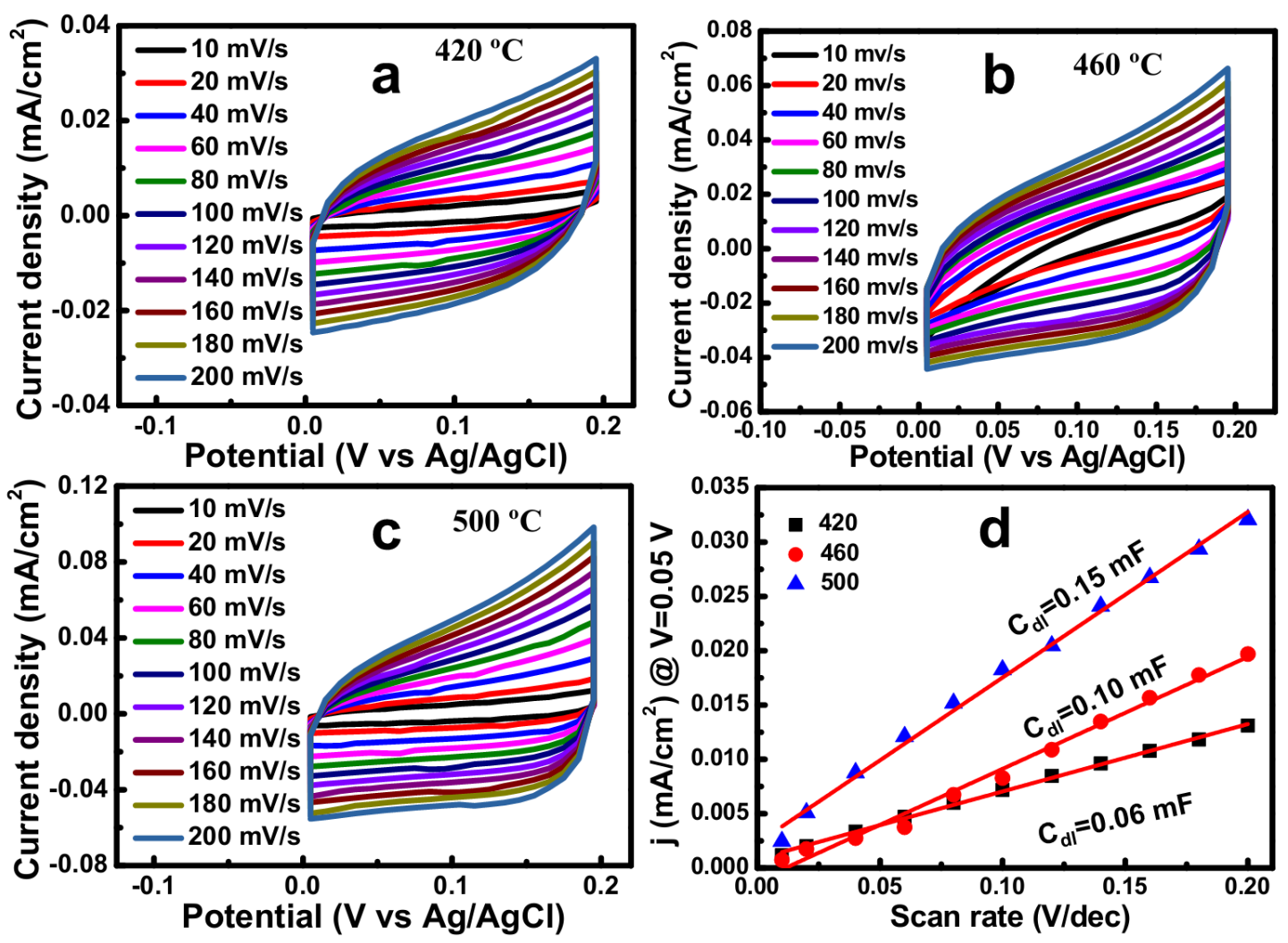

Figure S7. (a-c) CVs of CuO-3 sample annealed at different temperatures $\left(420^{\circ} \mathrm{C}\right.$, $460{ }^{\circ} \mathrm{C}$, and $500{ }^{\circ} \mathrm{C}$ ) from 0 to $+0.2 \mathrm{~V}$ vs. $\mathrm{Ag} / \mathrm{AgCl}$ at various scan rate in $1.0 \mathrm{M} \mathrm{KOH}$ solution. (d) The anodic current density measured at $0.05 \mathrm{~V}$ vs. $\mathrm{Ag} / \mathrm{AgCl}$ as a function of scan rate for $\mathrm{CuO}-3$ sample annealed at different temperatures. 

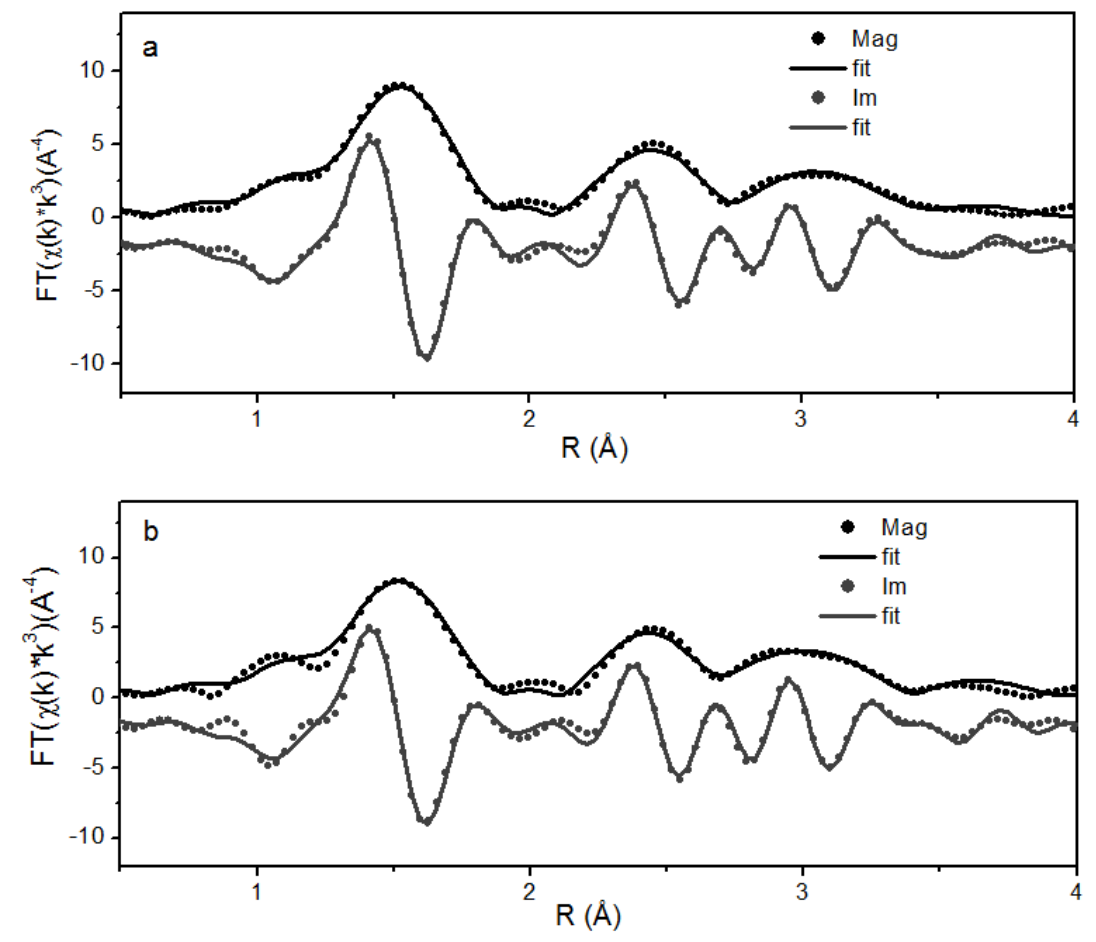

Figure S8. The Fourier transformed EXAFS spectra and their best fit of (a) $\mathrm{CuO}$ reference and (b) CuO-3 sample. The spectra are phase uncorrected, so the distance $\mathrm{R}$ in the figure are smaller than the actual values. 